\title{
Efficacy of Essential Oils from Edible Plants as Insecticides Against the House Fly, Musca Domestica L.
}

\section{Sara M. Palacios ${ }^{1, *}$, Alberto Bertoni ${ }^{1}$, Yanina Rossi ${ }^{1}$, Rocío Santander ${ }^{2}$ and Alejandro Urzúa ${ }^{2}$}

1 Laboratory of Fine Chemicals and Natural Products, Faculty of Chemical Sciences. Catholic University of Córdoba, Camino a Alta Gracia Km 10, (5000) Córdoba, Argentina. Fax: 03514938061. Tel.: 0351-4938060; E-mails: bertonialberto@hotmal.com (A.B.); yanirro@hotmail.com (Y.R.)

2 Facultad de Química y Biología, Universidad de Santiago de Chile, Casilla 40, Correo 33, Santiago, Chile. Phone: 56-2-7181155; Fax: 56-2-6812108; E-mail: aurzuamoll44@yahoo.com (A.U.); rocio.santander@gmail.com (R.S.)

* Author to whom correspondence should be addressed; E-mail: sarapalacios@ucc.edu.ar

Received: 14 April 2009; in revised form: 15 May 2009 / Accepted: 18 May 2009 /

Published: 25 May 2009

Abstract: The compositions of 12 essential oils (EOs) obtained by hydrodistillation of edible fruits and herbs were analyzed by gas chromatography/mass spectroscopy (GC/MS). The insecticidal activity of each oil against the house fly Musca domestica was evaluated by placing flies in a glass jar with a screw cap that held a piece of EO-treated cotton yarn. The dose necessary to kill $50 \%$ of flies $\left(\mathrm{LC}_{50}\right)$ in 30 min was determined at $26 \pm 1{ }^{\circ} \mathrm{C}$. Twelve EOs and 17 individual terpenes were assayed against $M$. domestica, showing $\mathrm{LC}_{50}$ values ranging from 3.9 to 85.2 and from 3.3 to $>100 \mathrm{mg} / \mathrm{dm}^{3}$, respectively. EO from Citrus sinensis was the most potent insecticide $\left(\mathrm{LC}_{50}=3.9 \mathrm{mg} / \mathrm{dm}^{3}\right)$, followed by EOs from C. aurantium $\left(\mathrm{LC}_{50}=4.8 \mathrm{mg} / \mathrm{dm}^{3}\right)$ and Eucalyptus cinerea $\left(\mathrm{LC}_{50}=5.5 \mathrm{mg} / \mathrm{dm}^{3}\right)$. According to GC/MS analysis, limonene (92.47\%), linalool (1.43\%), and $\beta$-myrcene $(0.88 \%)$ were the principal components of $C$. sinensis EO. Limonene was also the principal constituent $(94.07 \%)$ of C. aurantium, while 1,8-cineole $(56.86 \%)$ was the major constituent of E. cinerea EO. 1,8-Cineole was most active against $M$. domestica $\left(\mathrm{LC}_{50}=\right.$ $\left.3.3 \mathrm{mg} / \mathrm{dm}^{3}\right)$, while $(4 R)(+)$-limonene, was moderately active $\left(\mathrm{LC}_{50}=6.2 \mathrm{mg} / \mathrm{dm}^{3}\right)$. Dimethyl 2,2-dichlorovinyl phosphate (DDVP) selected as a positive control, showed an $\mathrm{LC}_{50}$ of $0.5 \mathrm{mg} / \mathrm{dm}^{3}$. EOs from C. sinensis, C. aurantium, and E. cinerea show promise as natural insecticides against houseflies. 
Keywords: Musca domestica; natural insecticide; essential oils; Citrus sinensis; Eucalyptus cinerea

\section{Introduction}

The housefly, Musca domestica L., is one of the most common insects, intimately associated with human settlements, food, and utensils. Flies feed and breed on decaying matter, human waste, and food, and are therefore considered to be mechanical vectors of pathogens such as bacteria, protozoa, and viruses. The housefly is categorized by the U.S. Food and Drug Administration as an important contributing factor in the dissemination of various infectious food-borne diseases such as cholera, shigellosis, and salmonellosis [1]. Adult houseflies have been shown to transmit pathogens from their sponging mouthparts, through vomitus, on their body and leg hairs, on the sticky parts of the feet, and through the intestinal tract, [2] thereby contaminating food and propagating disease.

Many insecticides such as organochlorines and organophosphates, and more recently pyrethroids and spinosad, have been used for housefly control. However, houseflies can develop resistance to these pesticides $[3,4]$ and health and environmental risks are associated with these compounds; thus, investigators continue to search for alternative methods of fly management. In this sense, essential oils (EOs) and natural terpenes (Ts) are potential alternatives and environmental friendly insecticides [5-7].

The toxicity of Ts against $M$. domestica has been studied extensively by Coats et al. [8] who demonstrated their insecticidal activity against a variety of insects via topical application. Among 33 Ts tested topically on $M$. domestica, thymol and pulegone were found to be the most active; the concentrations required to kill $50 \%$ of the insects $\left(\mathrm{LC}_{50}\right)$ were 29 and $39 \mu \mathrm{g} / \mathrm{fly}$, respectively [9]. However, $d$-limonene was more active than pulegone $\left(\mathrm{LC}_{50}=10\right.$ and $166 \mu \mathrm{g} / \mathrm{fly}$, respectively) when applied topically to female houseflies [8]. In a study in which monoterpenoid ester derivatives were synthesized from their parent alcohol or phenol, the parent compound was generally the more active compound against $M$. domestica [10].

An investigation of topical versus fumigant toxicity for a group of Ts revealed different levels of effectiveness for the same terpene (T). For instance, the most toxic topically applied Ts were, in descending order, thymol, citronellic acid, and citronellal, with topical $\mathrm{LC}_{50} \mathrm{~s}$ of 33, 43, and $60 \mu \mathrm{g} / \mathrm{fly}$, respectively. Within the same group of $\mathrm{Ts}$, the best fumigants were citronellal, menthol, and $l$-fenchone, with fumigant $\mathrm{LC}_{50} \mathrm{~S}$ of $2,3.6$, and $3.8 \mu \mathrm{g} / \mathrm{cm}^{3}$ [11]. The authors' explanation for the differences in activity of a given $\mathrm{T}$ was that fumigant toxicity is a function of terpene volatility. A bioassay on adult house flies using topical application of 1,8-cineole indicated that males were more susceptible than females, with $\mathrm{LC}_{50}$ values of 118 and $177 \mu \mathrm{g} / \mathrm{fly}$, respectively [12]. Phenols like thymol, and carvacrol were more topically toxic than saturated alcohols, but saturated alcohols were better fumigants against houseflies than were phenols [11].

Extensive study on the insecticidal properties of Ts has demonstrated that a given $\mathrm{T}$ has different levels of activity in different insects [11,13] and that Ts belonging to the same chemical family seem to have different modes of action in the same insects [14].

Data on the topical and fumigant activity of EOs against $M$. domestica are scarce [15]. Matricaria chamomilla and Clerodendron inerme EOs have topical $\mathrm{LC}_{50} \mathrm{~S}$ of 76 and $84 \mu \mathrm{g} /$ fly, respectively [16]. 
EOs from Citrus sinensis and C. aurantifolia peel showed 70\% fumigant effectiveness in killing house flies in a room after 60 min of spraying [17]. The insecticidal properties of lemon peel, grapefruit, and navel orange citrus oils against adults and larvae of $M$. domestica have been investigated [18], and grapefruit peel oil was toxic to $M$. domestica adults while lemon oil was toxic to larvae. Piper betle EO showed a fumigant $\mathrm{LC}_{50}$ of $10.3 \mathrm{mg} / \mathrm{dm}^{3}$ in a 24-h exposure period [19]. More recently, 34 EOs were screened against the housefly, and Pogostemon cablin EO was found to be the most potent topical insecticide, with an $\mathrm{LD}_{50}$ of $3 \mu \mathrm{g} / \mathrm{fly}$; Mentha pulegium oil was the most potent fumigant insecticide $\left(\mathrm{LC}_{50}=4.7 \mu \mathrm{g} / \mathrm{cm}^{3}\right)$ [20].

Many studies have evaluated of the use of Ts for controlling larvae and adult house flies in areas where this insect develops, but little has been done to evaluate Ts or EOs as fumigants in areas involved in food preparation or consumption or in domestic areas. Therefore, the literature offers little guidance as to the best choice of EO for use in a human environment. For instance, the reported $\mathrm{LC}_{50}$ values of EOs or Ts were determined at $24 \mathrm{~h}$ or more after topical application or after $24 \mathrm{~h}$ of exposure. In order to control flies that threaten food dishes, EOs must be effective within a shorter period. In addition, most previous studies did not report the bioassay temperature as being an important parameter with regard to volatile compounds. In this study, we evaluated the effectiveness of 12 EOs derived from edible plants and fruits against $M$. domestica after $30 \mathrm{~min}$ of exposure in order to select the best candidate for the formulation of new household products.

\section{Results and Discussion}

The compositions of each of the 12 EOs were consistent with previously reported compositions; the main components are listed in Table 1. The fumigant effects of EOs against adult $M$. domestica were evaluated by determining the $\mathrm{LC}_{50}$ values, which are presented in Table 2 . The most effective insecticide was the EO derived from $C$. sinensis, followed by C. aurantium and E. cinerea, with $\mathrm{LC}_{50}$ values of $3.9,4.8$, and $5.5 \mathrm{mg} / \mathrm{dm}^{3}$ of air respectively. EOs derived from other citrus species were also very effective against $M$. domestica, with $\mathrm{LC}_{50}$ values ranging from 6.5 to $7 \mathrm{mg} / \mathrm{dm}^{3}$. Some EOs were modestly to marginally effective, requiring doses from 8.8 to more than $25 \mathrm{mg} / \mathrm{dm}^{3}$ to induce $50 \%$ mortality. However, all EOs could kill some individual $M$. domestica adults within 30 minutes.

To determine whether contact toxicity contributed to the insecticidal properties of the various EOs, bioassays using of the most active EOs (sweet orange, sour orange, and eucalyptus) were conducted such that $M$. domestica could not come into contact with the cotton; similar mortality rates were observed (data not shown). This result was expected because contact and fumigant toxicity cannot be differentiated in cases of volatile compounds, since the compounds can reach any part of the fly body and our flies had full access to the entire test vessel. 
Table 1. Components (percent) of the essential oil assayed.

\begin{tabular}{|c|c|c|c|c|c|c|c|c|c|c|c|c|c|}
\hline & $R I$ & Cau & Cl & $C p$ & $\mathrm{Cr}$ & Cs & $C s a$ & $E c$ & Ln & $M f$ & $M p$ & $P a$ & $S a$ \\
\hline$\alpha$-Thujene & 924 & & & & & & & & & 1.13 & & & \\
\hline$\alpha$-Pinene & 932 & & 2.35 & & 1.62 & & 5.63 & 6.42 & 3.90 & 8.25 & & & \\
\hline Sabinene & 961 & & & 1.21 & & & & & & & & & \\
\hline$\beta$-Pinene & 970 & & 9.59 & & & & & & & & & & \\
\hline$\beta$-Myrcene & 983 & & & 2.62 & 2.49 & 0.88 & & & 1.21 & 3.96 & & & \\
\hline$\alpha$-Phellandrene & 1002 & & & & & & & & & 1.52 & & & \\
\hline$\delta$-3-Carene & 1008 & & & & & & & & & 1.90 & & & \\
\hline$\alpha$-Terpinene & 1014 & & & & & & & & & 5.28 & & & \\
\hline Limonene $^{\mathrm{a}}$ & 1027 & 94.07 & 49.56 & 94.97 & 82.83 & 92.47 & & & & & & & \\
\hline m-Cymene & 1030 & & & & & & 4.34 & & & & & & \\
\hline 1,8-Cineol & 1035 & & & & & & & 56.86 & 21.66 & & 6.73 & & \\
\hline$\delta$-Terpinene & 1050 & & 10.18 & & 10.89 & & 6.55 & & 1.40 & 7.14 & & & \\
\hline$\alpha$-Terpinolene & 1082 & & 1.76 & & & & & & & 3.42 & & & \\
\hline Linalool & 1121 & & & & & 1.43 & 63.56 & & 11.90 & & & & \\
\hline Camphor & 1137 & & & & & & 5.36 & & & & & & \\
\hline Menthone & 1144 & & & & & & & & & & 20.88 & & \\
\hline Mentol & 1164 & & & & & & & & & & 41.51 & & \\
\hline Terpinen-4-ol & 1182 & & 3.17 & & & & & 1.24 & 3.36 & 13.69 & & & \\
\hline Terpineol & 1190 & & 6.35 & & & 0.28 & & & & 1.82 & & & \\
\hline Estragole & 1195 & & & & & & & & & & & 3.42 & \\
\hline Pulegone & 1234 & & & & & & & & & & 2.57 & & \\
\hline p-Anisaldehyde & 1240 & & & & & & & & & & & 6.31 & \\
\hline Geraniol & 1265 & & & & & & 2.86 & & & & & & \\
\hline Safrol & 1275 & & & & & & & & & 5.21 & & & \\
\hline trans-Anethole & 1282 & & & & & & & & & & & 68.76 & \\
\hline Neryl acetate & 1359 & & 3.61 & & & & & & & & & & \\
\hline Eugenol & 1366 & & & & & & & & 2.90 & & & & 63.26 \\
\hline Geranyl acetate & 1379 & & 1.06 & & & & 4.87 & & & & & & \\
\hline Eugenol methyl & 1408 & & & & & & & & 8.10 & & & & \\
\hline$\beta$-Caryophyllene & 1408 & & & & & & & & & 1.00 & & & 22.62 \\
\hline$\alpha$-Humulene & 1452 & & & & & & & & & & & & 3.43 \\
\hline$\alpha$-Himachalene & 1490 & & & & & & & & & & & 11.88 & \\
\hline$\beta$-Bisabolene & 1530 & & 1.25 & & & & & & & & & 1.25 & \\
\hline Eugenyl acetate & 1546 & & & & & & & & & & & & 6.28 \\
\hline Caryophyllene oxide & 1582 & & & & & & & & & & 1.20 & & \\
\hline
\end{tabular}

Cau, Citrus aurantium; Cl, Citrus limon; Cp, Citrus paradise; Cr, Citrus reticulata; Cs, Citrus sinensis; Csa, Coriandrum sativum; Ec, Eucalyptus cinerea; Ln, Laurus nobilis; Mf, Myristica fragrans; Mp, Mentha piperita; Pa, Pimpinella anisum; Sa, Syzygium aromaticum. a) $(4 R)(+)$-limonene $>99 \%$ by GC chiral columna, see experimental section. 
Table 2. $\mathrm{LC}_{50} \mathrm{~s}$ of essential oils against Musca domestica.

\begin{tabular}{lc}
\hline \multicolumn{1}{c}{ Essential oil } & Mean $\mathrm{LC}_{50}$ in $\mathrm{mg} / \mathrm{dm}^{3}(95 \% \mathrm{CI})$ \\
\hline Citrus aurantium & $4.8(3.7-6.3)$ \\
Citrus limon & $6.5(1.5-27.4)$ \\
Citrus paradisi & $6.8(2.9-15.7)$ \\
Citrus reticulata & $7(2.7-18.3)$ \\
Citrus sinensis & $3.9(1.2-13)$ \\
Coriandrum sativum & $6.9(3.7-13)$ \\
Eucalyptus cinerea & $5.5(4.1-7.4)$ \\
Laurus nobilis & $6.2(1.8-21.1)$ \\
Mentha piperita & $24.1(5.9-98.7)$ \\
Myristica fragrans & $8.8(3-26)$ \\
Pimpinella anisum & $22.4(3.4-148.9)$ \\
Syzygium aromaticum & $85.2(2.6-276.8)$ \\
\hline
\end{tabular}

The insecticidal activities of the most abundant Ts in some of the EOs were compared with the insecticidal activities of the EOs themselves (Table 3). In general, the Ts were less active than the EOs. The most active $\mathrm{T}$ was 1,8 -cineole $\left(\mathrm{LC}_{50}=3.3 \mathrm{mg} / \mathrm{dm}^{3}\right)$, followed by $\gamma$-terpinene, $(4 S)(-)-$ limonene, $\alpha$-terpinene, and $(4 R)(+)$-limonene, with $\mathrm{LC}_{50} \mathrm{~s}$ of $4,5,6.2$, and $6.2 \mathrm{mg} / \mathrm{dm}^{3}$, respectively.

Table 3. $\mathrm{LC}_{50} \mathrm{~S}$ of selected terpenes against Musca domestica.

\begin{tabular}{lc}
\hline \multicolumn{1}{c}{ Terpene } & Mean $\mathrm{LC}_{50}$ in $\mathrm{mg} / \mathrm{dm}^{3}(95 \% \mathrm{CI})$ \\
\hline trans-anethole & $20.5(3.9-107.1)$ \\
carvacrol & $45.4(17.1-120.8)$ \\
citronellal & $8.1(2.8-23.5)$ \\
1,8-cineole & $3.3(1.1-10.4)$ \\
eugenol & $98.4(0.2-55137.1)$ \\
$(4 R)(+)-$ limonene & $6.2(1.7-23)$ \\
$(4 S)(-)-$ limonene & $5(2.4-10.4)$ \\
linalool & $13.6(0.5-348.6)$ \\
menthol & $>100$ \\
$( \pm)-\alpha-$ pinene & $11.5(3.6-37.3)$ \\
$(1 R)(+) \alpha-$ pinene & $12.1(9.5-15.5)$ \\
$(1 S)(-) \alpha-$ pinene & $8.9(2.6-30.8)$ \\
$(1 S)-(-) \beta-p i n e n e$ & $6.4(2.4-17.4)$ \\
$\alpha$-terpinene & $6.2(2.8-13.7)$ \\
$\gamma$-terpinene & $4(1.5-10.9)$ \\
terpineol & $36.8(21.1-63.9)$ \\
thymol & $13(2.4-68.7)$ \\
dimethyl 2,2-dichlorovinyl & $0.5(0.11-2.06)$ \\
phosphate (DDVP) &
\end{tabular}

1,8-Cineole was present in the EO from E. cinerea, L. nobilis and M. piperita, (in order of descending concentration). The proportion of 1,8-cineole in the E. cinerea EO was $56.86 \%$, which means that the $\mathrm{LC}_{50}$ dose of E. cinerea $\mathrm{EO}$ contains approximately $3.14 \mathrm{mg}$ of 1,8-cineole. This 
suggests that 1,8-cineole is the primary active component in E. cinerea EO. However, the presence of 1,8-cineole in other EOs does not seem to influence the magnitude of their $\mathrm{LC}_{50} \mathrm{~S}$ greatly, since the proportion of 1,8 -cineole in those EOs did not correlate $\left(\mathrm{r}^{2}=0.57\right)$ with the corresponding $\mathrm{LC}_{50}$.

Neither $\delta$-terpinene nor $\alpha$-terpinene was a major component in any EO studied, and their presence did not seem to influence the activity of the $\mathrm{EO}$ that contained them. The $\mathrm{LC}_{50} \mathrm{~S}$ of $(4 S)(-)$-limonene and $(4 R)(+)$-limonene were 5 and $6.2 \mathrm{mg} / \mathrm{dm}^{3}$, respectively; however, the Citrus EO used in this study contained only $(4 R)(+)$-limonene [21,22] (Table 1). Therefore, we compared the $\mathrm{LC}_{50}$ of Citrus EOs with the $\mathrm{LC}_{50}$ of $(4 R)(+)$-limonene and found that $(4 R)(+)$-limonene, the fourth most active $\mathrm{T}$, had the same insecticidal activity as Citrus EOs. Although its presence in citrus peel-derived EOs could help to explain the activity of Citrus EOs, it is remarkable that sweet orange EO, consisting of $92.47 \%$ limonene, was more active $\left(\mathrm{LC}_{50}=3.9 \mathrm{mg} / \mathrm{dm}^{3}\right)$ than $(4 R)(+)$ - limonene. The $C$. paradisi $\mathrm{EO}\left(\mathrm{LC}_{50}=\right.$ $6.8 \mathrm{mg} / \mathrm{dm}^{3}$ ), containing $94.97 \%$ limonene, showed a toxicity similar to that of $(4 R)(+)$-limonene, but was less active than $C$. sinensis EO. Moreover, we found no correlation between the proportion of limonene in Citrus EO and the $\mathrm{LC}_{50}\left(\mathrm{r}^{2}=0.15\right)$.

Dimethyl 2,2-dichlorovinyl phosphate (DDVP) selected as a positive control, showed an $\mathrm{LC}_{50}$ of $0.5 \mathrm{mg} / \mathrm{dm}^{3}$ (Table 3). The most active EO, C. sinensis, and the most active T, 1,8-cineole, were about 7.8- and 6.6-times less active than DDVP, respectively. Therefore, the EO of C. sinensis for example, could compete with synthetic insecticides as a fumigant in the control of $M$. domestica. The need for higher doses of these compounds does not pose a health problem because Citrus EOs are not highly toxic to humans, nor does it pose an environmental problem because EOs are biodegradable.

When treated with these EOs, $M$. domestica exhibited classic signs of neurotoxicity, such as overt hyperactivity, loss of coordination, and tremors. Similar signs were described previously for exposure to pure monoterpenes [8]. Despite abundant research, the modes of action of monoterpenes or EOs are not well understood. Research has shown that some Ts have affinity for acetylcholinesterase [23] while others bind to octopamine receptors [24]. Quantitative structure-activity relationship (QSAR) studies on the insecticidal activity of thymol- and methyl-cyclohexyl-related monoterpenes against $M$. domestica demonstrated that the mode of action of these compounds might not be defined exclusively by one mechanism [25].

\section{Experimental}

\subsection{General}

Trans-Anethole, carvacrol; citronellal, 1,8-cineole; eugenol; $(4 R)(+)-$ limonene; $(4 S)(-)$-limonene; linalool; menthol; $( \pm)$ - $\alpha$-pinene; $(1 R)(+)$ - $\alpha$-pinene; $(1 S)(-)$ - $\alpha$-pinene; $(1 S)(-) \beta$-pinene; $\alpha$-terpinene; $\gamma$ terpinene; terpineol and thymol were purchased from Sigma-Aldrich (St. Louis, MO, USA). HPLCgrade acetone was purchased from Merck (Darmstadt, Germany). Dimethyl-2,2-dichlorovinyl phosphate (DDVP) was a gift of Professor H. Masuh, from Center of Investigation on Pests and Insecticides, CONICET, Argentina. EO component analysis was performed by gas chromatography/ mass spectroscopy (GC/MS) on a Hewlett-Packard 5890 GC interfaced with a Hewlett-Packard 5970 Series mass spectrometer fitted with a HP-5MS column $(15 \mathrm{~m} \times 0.25 \mathrm{~mm}$ inner diameter $)$. A chiral column (SUPELCO-beta-DEX 120, $60 \mathrm{~m} \times 0.25 \mathrm{~mm}$ inner diameter) was used to resolve enantiomers. 


\subsection{Plant material}

Twelve aromatic edible plants or fruits were selected: Citrus aurantium L. (bitter orange) fruit peel, Citrus limon L. (lemon) fruit peel, Citrus paradisi Macf. (grapefruit) fruit peel, Citrus reticulata Blanco (mandarin) fruit peel, Citrus sinensis L. (sweet orange) fruit peel, Coriandrum sativum L. (coriandrum) seeds, Eucalyptus cinerea F. v. Muell. (eucalyptus) leaves, Laurus nobilis L. (bay) leaves, Mentha piperita L. (peppermint) leaves, Myristica fragrans Houtt. (nutmeg) nut, Pimpinella anisum L. (anise) seeds and Syzygium aromaticum (L.) Merr. \& Perry. (cloves) dried flower buds. The fruits and leaves were obtained from domestic organic fruit gardens. Seeds and nuts were purchased from local grocery stores.

\subsection{Essential oil extraction and analysis}

Essential oils were extracted for $2 \mathrm{~h}$ by hydrodistillation in a Clevenger-type apparatus with a separated extraction chamber. The EOs were dried over anhydrous sodium sulfate. EO component analysis was performed by gas chromatography/mass spectroscopy (GC/MS) using the instrumentation described above. The temperature program was $50^{\circ}$ to $240^{\circ} \mathrm{C}$ at $5^{\circ} \mathrm{C} / \mathrm{min}$. Helium was used as the carrier gas (flow rate $=0.9 \mathrm{~mL} / \mathrm{min}$ ). Chiral analyses were performed with the same temperature program. The mass spectra were obtained at an ionization voltage of $70 \mathrm{eV}$. The identification of compounds in the chromatographic profiles was achieved by comparison of their mass spectra with a library database (NIST, version 3.0), and was confirmed by comparison of retention indices with those of authentic standards (terpenes listed in Section 3.1) or with values from the literature. The percentage composition of the oils was computed by area normalization method from GC peak areas calculated as the mean value of two injections from each oil.

\subsection{Fly collection and maintenance}

Colonies of $M$. domestica originated from adults were collected from the experimental field of the Universidad Católica of Córdoba, in Córdoba, Argentina, using a sweep net. The flies were transferred to a small cage and then reared in entomological cages $(30 \times 30 \times 30 \mathrm{~cm})$ at $26( \pm 1){ }^{\circ} \mathrm{C}$ under a $12: 12$ light:dark cycle and $70 \%$ humidity. Adult flies were provided with water and fed a 1:1 (v/v; approximately) mixture of granulated sugar and powdered milk. Bran and milk were prepared at a weight ratio of $1: 3$ and $100 \mathrm{~g}$ of this mixture was placed on a plastic plate as an oviposition site.

\subsection{Bioassay}

The bioassay was designed such that the flies would have high probability of coming into contact with the volatile compounds within the 30 minute test period; therefore, the flies were allowed access to the total space within the exposure vessel. Ten 4-5 day-old adult house flies, mixed sexes, were placed in a glass jar $\left(1.2 \mathrm{dm}^{3}\right)$ fitted with a screw cap with a 7-cm length of cotton yarn suspended from the center of the internal face of the cap. Different dosages of pure EO (without solvent) were applied to the yarn. The control vessel had no compound on the cotton yarn. In cases of Ts that are solids at room temperature, such as menthol and thymol, each dose was applied after being dissolved in $10 \mu \mathrm{L}$ of acetone; in these cases, the cotton yarn in the control vessel was treated with $10 \mu \mathrm{L}$ of 
acetone. The jars were then sealed tightly. The jars were maintained in a room at $26 \pm 1{ }^{\circ} \mathrm{C}$. Each test was replicated three times. The assay was also run with the cotton yarn enclosed in a bag made of breathable cloth so that the flies could not contact the yarn. Dimethyl 2, 2-dichlorovinyl phosphate (DDVP), a volatile organophosphate, was used as a positive control. Mortality in each group was assessed after $30 \mathrm{~min}$ of exposure by softly stimulating each fly with the tip of a pen. Flies that did not respond were considered dead. The mean mortality data of the three replicates per doses (4-6 doses per EO or compound) was used to calculate the $\mathrm{LC}_{50}$. Probit analysis (Harvard Programming; $\mathrm{Hg} 1,2$ ) was used to analyze the dose-mortality response.

\section{Conclusions}

The above mentioned results indicate that: a) The EOs from C. sinensis, C. aurantium, and E. cinerea were highly toxic to adult houseflies, provoking death within a short period of time; $b$ ) in many cases, the EOs are more effective, as housefly fumigants, than their most abundant $\mathrm{T}$ component; c) the most active EO of this study, C. sinensis EO, showed in 30 min experiment a comparable $\mathrm{LC}_{50}$ $\left(=3.9 \mathrm{mg} / \mathrm{dm}^{3}\right)$ to that determined by Pavela et al. for Mentha pulegium $\left(\mathrm{LC}_{50}=4.7 \mathrm{mg} / \mathrm{dm}^{3}\right)$ at $24 \mathrm{~h}$ [20]; and d) EOs from C. sinensis, C. aurantium, and E. cinerea are highly effective and may be considered good candidates for development as fumigants that are compatible with food, property, and human habitats.

\section{Acknowledgements}

Financial support for this work was provided by Agencia Nacional de Promoción Científica y Técnica, FONCYT, PICT 33953.

\section{References and Notes}

1. Olsen, A.R.; Gecan, J.S.; Ziobro, G.C.; Bryce, J.R. Regulatory action criteria for filth and other extraneous materials: V. Strategy for evaluating hazardous and nonhazardous filth. Regul. Toxicol. Pharmacol. 2001, 33, 363-392.

2. De Jesús, A.J.; Olsen, A.R.; Bryce, J.R.; Whiting, R.C. Quantitative contamination and transfer of Escherichia coli from foods by houseflies, Musca domestica L. (Diptera: Muscidae). Int. J. Food Microbiol. 2004, 93, 259-262.

3. Scott, J.G.; Alefantis, T.G.; Kaufman, P.E.; Rutz, D.A. Insecticide resistance in house flies from caged-layer poultry facilities. Pest Manag. Sci. 2000, 56, 147-153.

4. Shono, T.; Scott, J.G. Spinosad resistance in the housefly, Musca domestica, is due to a recessive factor on autosome 1. Pest. Biochem. Physiol. 2003, 75, 1-7.

5. Regnault-Roger, C. The potential of botanical essential oils for insect pest control. Integr. Pest Manag. Rev. 1997, 2, 25-34.

6. Isman, M.B. Plant essential oils for pest and disease management. Crop Protect. 2000, 19, 603608. 
7. Isman, M.B.; Machial, C.M. Pesticides based on plant essential oils: from traditional practice to commercialization. In Advances in Phytomedicine; Rai, M., Carpinella, M.C., Eds.; Elsevier: Amsterdam, The Netherlands, 2006; pp. 29-44.

8. Coats, J.R.; Karr, L.L.; Drewes, C.D. Toxicity and neurotoxic effects of monoterpenoids in insects and earthworms. In Naturally Occuring Pest Bioregulators. ACS Symposium Series 449, Hedin, P.A., Ed.; ACS: Washington, DC, USA, 1991; pp. 306-316.

9. Lee, S.; Tsao, R.; Peterson, C.; Coats, J.R. Insecticidal activity of monoterpenoids to western corn rootworm (Coleoptera: Chrysomelidae), twospotted spider mite (Acari: Tetranychidae), and housefly (Diptera: Muscidae). J. Econ. Entomol. 1997, 90, 883-892.

10. Rice, P.J.; Coats, J.R. Structural requirements for monoterpenoid activity against insects. In: Bioregulators for crop protection and pest control, ACS Symposium Series 557, $1^{\text {st }}$ Ed.; Hedin, P.A., Ed.; ACS: Washington, D.C., USA, 1994; pp. 92-108.

11. Rice, P.J.; Coats, J.R. Insecticidal properties of several monoterpenoids to the house fly (Diptera: Muscidae), red flour beetle (Coleoptera: Tenebrionidae) and southern corn rootworm (Coleoptera: Chrysomelidae). J. Econ. Entomol. 1994, 87, 1172-1179.

12. Sukontason, K.L.; Boonchu, N.; Sukontason, K.; Choochote, W. Effects of eucalyptol on house fly (Diptera: Muscidae) and blow fly (Diptera: Calliphoridae). Rev. Inst. Med. Trop. S. Paulo 2004, 46, 97-101.

13. Rice, P.J.; Coats, J.R. Insecticidal properties of monoterpenoids derivatives to the house fly (Diptera: Muscidae), and red flour beetle (Coleoptera: Tenebrionidae). Pestic. Sci. 1994, 41, 195 202.

14. Lee, B.H.; Choi, W.S.; Lee, S.E.; Park, B.S. Fumigant toxicity of essential oils and their constituent compounds towards the rice weevil, Sitophilus oryzae (L.). Crop Protect. 2001, 20, 317-320.

15. Malik, A.; Singh, N.; Satya, S. House fly (Musca domestica): A review of control strategies for a challenging pest. J. Environ. Sci. Health. B. 2007, 42, 453-469.

16. Shoukry, I.F. Toxicological deteriorations of two volatile oils of Matricaria chamomilla and Clerodendron inerme on the adult house fly Musca domestica L. J. Egypt. Soc. Parasitol. 1997, 27, 893-904.

17. Ezeonu, F.C.; Chidume, G.I.; Udedi, S.C. Insecticidal properties of volatile extracts of orange peels. Biores. Technol. 2001, 76, 273-274.

18. Shalaby, A.A.; Allam, K.A.; Mostafa, A.A.; Fahmy, S.M. Insecticidal properties of citrus oils against Culex pipiens and Musca domestica. J. Egypt. Soc. Parasitol. 1998, 28, 595-606.

19. Mohottalage, S.; Tabacchi, R.; Guerin, P.M. Components from Sri Lankan Piper betle L. leaf oil and their analogues showing toxicity against the housefly, Musca domestica. Flavour Frag. J. 2007, 22, 130-138.

20. Pavela, R. Insecticidal properties of several essential oils to the House Fly (Musca domestica L.). Phytotherapy Res. 2008, 22, 274-278.

21. del Castillo, M.L.R.; Caja, M.M.; Herraiz, M. Use of the enantiomeric composition for the assessment of the authenticity of fruit beverages. J. Agric. Food Chem. 2003, 51, 1284-1288. 
22. Haudenschild, C.; Schalk, M.; Karp, F.; Croteau, R. Functional expression of regiospecific cytochrome P450 limonene hydroxylases from mint (Mentha spp.) in Escherichia coli and Saccharomyces cerevisiae. Arch. Biochem. Biophys. 2000, 379, 127-136.

23. Ryan, M.F.; Byrne, O. Plant-Insect coevolution and inhibition of acetylcholinesterase. J. Chem. Ecol. 1998, 14, 1965-1975.

24. Enan, E. Insecticidal activity of essential oils: Octopaminergic sites of action. Comp. Biochem. Physiol.,C: Toxicol. Pharmacol. 2001, 130, 325-337.

25. Grodnitzky, J.A.; Coats, J.R. QSAR Evaluation of Monoterpenoids' Insecticidal Activity. J. Agric. Food Chem. 2002, 50, 4576-4580.

Sample Availability: Samples of the essential oils are available from the authors.

(C) 2009 by the authors; licensee Molecular Diversity Preservation International, Basel, Switzerland. This article is an open-access article distributed under the terms and conditions of the Creative Commons Attribution license (http://creativecommons.org/licenses/by/3.0/). 